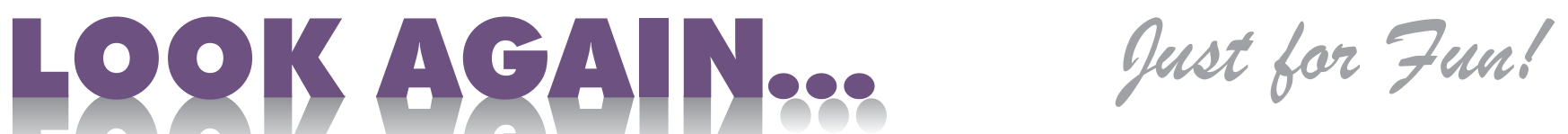

See if you can find the 8 differences

in each set of images.

Newborn star absorbs interstellar dust

This optical microscope image shows the assembly of colloidal photonic crystals (green strips on the left side) onto a polymer microsphere. The photonic materials are silica-coated magnetite nanoclusters and the polymer microspheres are made of Polyethylene Glycol Diacrylate. The sizes of microspheres are $\sim 100 \mu \mathrm{m}$.

Mingsheng Wang, University of California-Riverside, USA
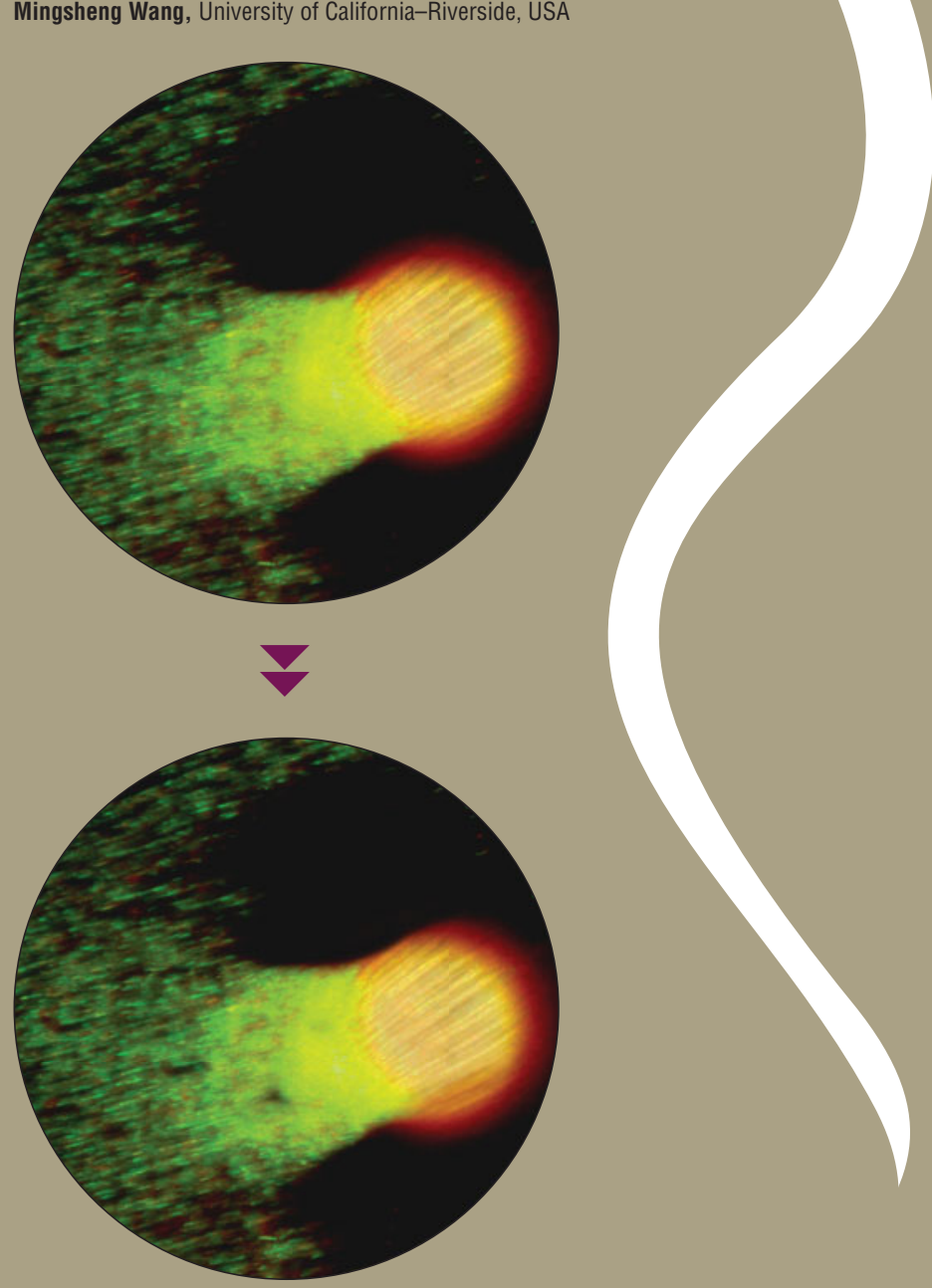

June 2013 answer key


\section{Pop-art tree of life}

A DNA liquid-crystal phase in a droplet of salmon DNA water solution. The original photo was taken under a polarized light microscope with a full wave retardation plate, with magnification of 20x. The eight subsequent images were created in an image processing software.

Joanna Olesiak-Banska, Katarzyna Matczyszyn, and Marek Samoc, Wrocław University of Technology, Poland
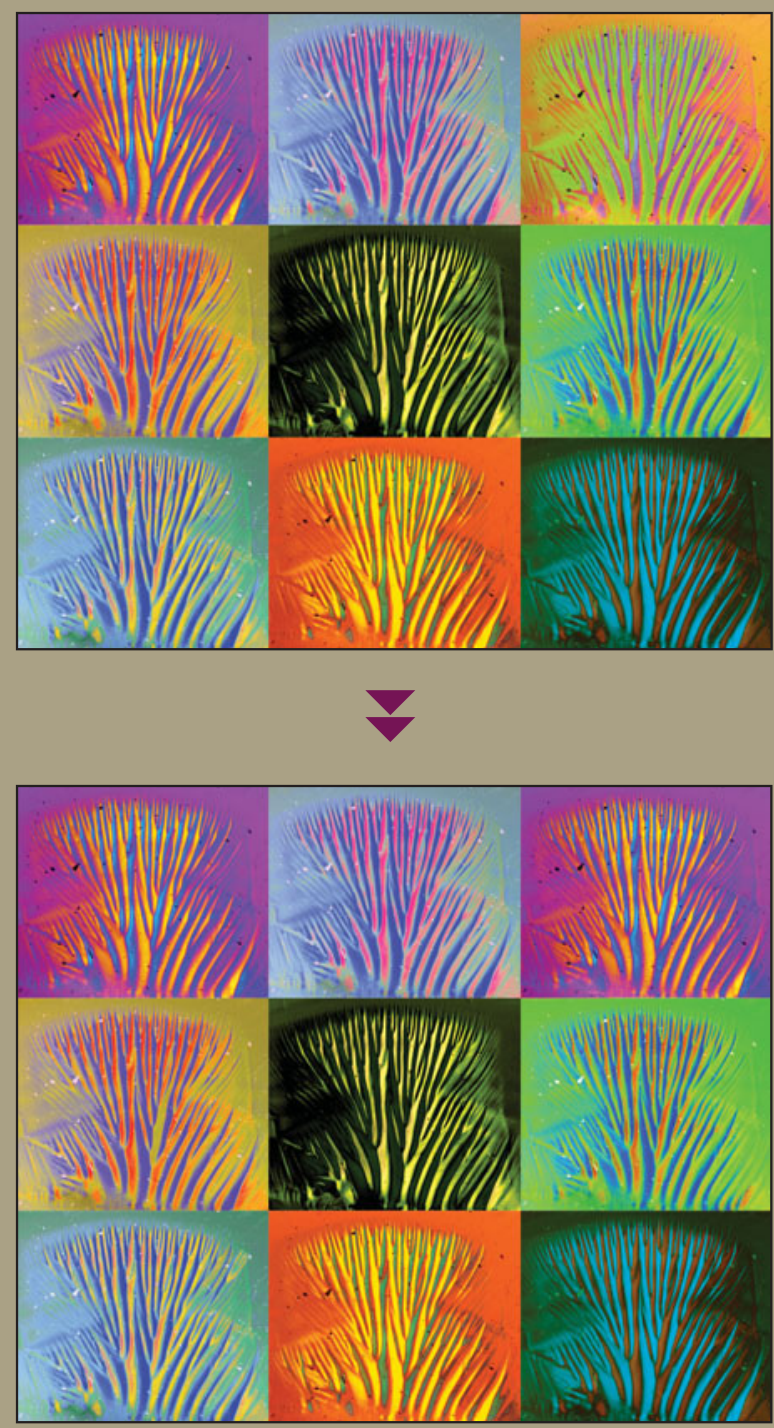

Images on the top were submitted to the Materials Research Society "Science as Art" competition.

Images on the bottom were modified in Adobe Photoshop for this "Look Again" activity. 